\section{Estratégias e}

\section{mobilidade social:}

\section{o acesso de}

\section{descendentes}

\section{de escravos e}

libertos ao

clero secular no

bispado do

Rio de Janeiro

$(1702-1745)^{1}$

\section{Anderson José Machado} de Oliveira [*]

[*] Coordenador do Programa de Pós-graduação em História e pesquisador do Ecclesia: Grupo de Estudos de História do Catolicismo/Universidade Federal do Estado do Rio de Janeiro (Unirio). Rio de Janeiro (RJ), Brasil.

andersonoliveira.17@hotmail.com

ORCID: https://orcid.org/0000-0002-4801-5434
Resumo: $\mathrm{O}$ artigo procura analisar o processo de mobilidade social de descendentes de escravos e libertos de origem africana na América portuguesa, destacando as estratégias executadas pelos grupos familiares no intuito de superar a mácula imposta pela escravidão. Nesse sentido, privilegia-se o papel da carreira eclesiástica em sociedades escravistas hierarquizadas com base em valores oriundos do Antigo Regime.

Palavras-chave: Estratégias; Mobilidade social; Família; Clero secular.

Strategies and social mobility: the access of descendants of slaves and freedmen to the secular clergy in bishopric of Rio de Janeiro (1702-1745)

\begin{abstract}
The article seeks to analyze the process of social mobility of African descendants of slaves and freedmen in Portuguese America, highlighting the strategies executed by family groups in order to overcome the macule imposed by slavery. In this sense, the role of the ecclesiastical career in hierarchical slave societies based on values derived from the Old Regime is privileged.
\end{abstract}

Keywords: Strategies; Social mobility; Family; Secular clergy.

Pesquisa financiada com recursos do Conselho Nacional de Desenvolvimento Científico e Tecnológico (CNPq) - bolsa produtividade. 


\section{Origens e trajetórias}

os seis dias do mês de fevereiro de 1708, o licenciado Francisco da Costa Maciel
entrou com uma petição junto à Câmara Eclesiástica do bispado do Rio de Janeiro,
solicitando que se lhe fizessem as investigações quanto às suas origens com o objetivo de receber todas as ordens sacras. O mesmo apresentou um breve apostólico que lhe dispensava para os defeitos da ilegitimidade e da $\operatorname{cor}^{2}{ }^{2} \mathrm{O}$ habilitando declarou ser filho natural do licenciado Bento Curvelo Maciel, sacerdote e vigário colado da matriz da vila de São Paulo que o tivera no estado secular com uma preta chamada Madalena da Conceição, que fora escrava e encontrava-se liberta. Pelo lado paterno Francisco era neto do capitão Antônio Curvelo Escudeiro e de dona Joana do Souto, pelo lado materno os avós foram identificados como pretos de Angola. ${ }^{3}$

As seis testemunhas ${ }^{4}$ que depuseram no processo de genere ${ }^{5}$ atestaram que conheciam o habilitando, seus pais e seus avós paternos, e que Francisco Maciel, assim como seus pais e avós, era inteiro e legítimo cristão velho, sem raça ou fama de nação infecta ou condenada em direito pela Santa Fé Católica, apesar de carregar o defeito da cor. O depoente Antônio Pedroso, escrivão das Bulas da Santa Cruzada, complementou sua declaração acrescentando que os avós paternos do habilitando eram "pessoas principais" da cidade. Destacavam-se ainda entre as testemunhas os irmãos padre Francisco Cabral de Távora e o sargento-mor Miguel Arias Maldonado, este último, padrinho de batismo do ordinando, além do doutor Luís Machado (Vide, 2012; Lemaitre, 2002). Vale ressaltar que a qualidade das testemunhas, no Antigo Regime, conferia credibilidade ao depoimento prestado (Olival et al., 2013, p. 335).

Em maio de 1708, o vigário-geral do Rio de Janeiro aprovou as certidões relativas à comprovação do patrimônio, sendo o dito composto por um lance de casas térreas na vila de

\footnotetext{
2 O defeito da cor definiu-se no âmbito das práticas processuais na medida em que nem as legislações sinodais e muito menos a legislação tridentina o previa. De forma geral, o impedimento da cor advinha da existência de uma origem que se relacionava à escravidão. Cf. Oliveira (2015, 2020).

${ }^{3}$ ACMRJ (Arquivo da Cúria Metropolitana do Rio de Janeiro) - HS (Habilitações Sacerdotais) - Francisco da Costa Maciel, 1708-1737.

${ }^{4}$ Segundo as Constituições primeiras do arcebispado da Bahia deveriam ser convocadas de sete a oito testemunhas, embora, na prática, isso tenha variado. Cf. Vide (2010, p. 824).

${ }^{5}$ O processo de ordenação sacerdotal era geralmente composto por três partes ou subprocessos: "genere" (investigação das origens familiares), "vita et moribus" (investigação dos costumes) e "patrimônio" ou benefício eclesiástico que se tornou uma exigência a partir do Concílio de Trento e previa a necessidade de comprovar que o habilitando, depois de ordenado, teria meios para manter-se honestamente. Objetivava-se com isso evitar que os sacerdotes vivessem como mendicantes, o que era visto como indigno ao estado clerical, além de prevenir abusos no que tangiam às práticas de simonia ou que exercessem atividades que Ihes eram proibidas, como, por exemplo, o comércio (Vide, 2010, p. 227; Lemaitre, 2002, p. 182)
} 
Nossa Senhora dos Remédios de Parati, região sul da capitania do Rio de Janeiro. As datas das inquirições, das autenticações dos breves apostólicos e do processo de patrimônio indicam que, em 1709, a habilitação de Francisco da Costa Maciel estava concluída. Passados 27 anos de sua ordenação, em 1736, padre Francisco solicitou a autuação de novo breve apostólico junto à Câmara Eclesiástica da diocese, agora com o propósito de reconhecer sua indicação ao cargo de notário apostólico. Em 1737, após examinar o indicado, o vigário-geral deu cumprimento ao breve, empossando-o na função. ${ }^{6}$

O período que se situa entre a ordenação e a assunção de padre Francisco ao notariado apostólico constituiu-se em uma lacuna que não consegui elucidar. Desse modo, somente é possível realizar algumas conjecturas quanto à sua trajetória pós-ordenação. Com efeito, sua nomeação demonstra que o padre gozava de algum prestígio e boas relações que garantiram a indicação apostólica para o exercício do ofício e sua colação na diocese. Os notários apostólicos poderiam ser nomeados diretamente pelo papa e, posteriormente, prestavam juramento perante o vice-chanceler em Roma. Essa modalidade de nomeação utilizava-se para os que não se fixavam em uma diocese específica. Outra modalidade dava-se por nomeação indireta do papa e dirigia-se àqueles que se fixariam em uma diocese específica para exercer o seu ofício. A colação era efetuada pelo bispo que procedia ao exame de idoneidade do indicado, segundo os critérios de boa filiação e vida digna, além de receber o juramento do candidato. Uma terceira modalidade produzia-se a partir da uma solicitação do bispo diocesano, que recebia do papa o direito de criar um número determinado de notários (Valverde, 2010).

O caso em questão parece ajustar-se à segunda modalidade, pois, segundo as Constituições primeiras do arcebispado da Bahia, os notários eram obrigados a mostrar os títulos de sua criação ao provisor ou vigário-geral do bispado para que fossem admitidos e examinados (Vide, 2010, p. 863). Desta feita, as relações locais eram importantes, pois, submetidos às regras do Auditório Eclesiástico, recaía sobre o bispo a admissão dos candidatos da mesma forma que a indicação e nomeação dos cargos de escrivão da Câmara Eclesiástica, quando os bispos diocesanos escolhiam pessoas de sua inteira confiança que atuariam como seus representantes não só na escrituração dos documentos do bispado, mas igualmente ajudando na fiscalização dos costumes dos fiéis. Com isso, os prelados, por meio dessas indicações e admissões, acabavam por reproduzir os mecanismos das relações clientelares que faziam funcionar o sistema político no Império português (Paiva, 2006, p. 286-287; Oliveira A. J., 2014, p. 357).

Saliente-se que o pai de padre Francisco da Costa Maciel era vigário de uma localidade importante, além da família paterna ser reconhecida entre as "principais" daquela socieda-

${ }^{6}$ ACMRJ - HS - Francisco da Costa Maciel, 1708-1737. 
de, fatores que podem ter favorecido sua empreitada. Um dos depoentes em sua habilitação de genere, Francisco de Bessa Castro, declarou ocupar o ofício de porteiro da massa, cargo que existia na estrutura das funções da Catedral do Rio de Janeiro desde 1681. ${ }^{7}$ Sob este aspecto, o padre teria alguma proximidade com pessoas relacionadas aos serviços episcopais, embora a função de porteiro não fosse das mais destacadas. No entanto, o sacerdote já havia demonstrado ter conexões importantes que propiciaram a solicitação dos breves de dispensa dos defeitos e o de indicação ao ofício de notário, já que os caminhos que permitiam a comunicação com a Santa Sé não eram os mais simples, demandando relações com agentes temporários ou permanentes em Roma que viabilizassem a chegada do pedido, assim como o seu retorno. Muitos desses agentes estavam ligados às instâncias da Igreja que os mantinham, a exemplo dos bispos, cabidos e ordens religiosas (Paiva, 2005, p. 171).

A função notarial, além do domínio da leitura e da escrita corrente, exigia o conhecimento do latim, na medida em que uma de suas atribuições era tratar de rescritos de bulas, breves e outras letras apostólicas. O fato de ter o título de licenciado indicava que padre Francisco havia ascendido aos graus universitários, o que de alguma forma deve tê-lo favorecido na indicação ao posto. Cabia ainda ao notário apostólico realizar diligências que podiam exceder o território eclesiástico em que se encontrava, além de passar certidões e colher depoimentos, desde que autorizado pelo provisor ou vigário-geral (Vide, 2010, p. 863-865).

A ordenação sacerdotal também foi o caminho buscado por Antônio Cabral da Fonseca que, assim como o padre Francisco da Costa Maciel, era filho de um padre e de uma mulher de cor. Em 171l, identificando-se como clérigo de primeira tonsura e como agregado e sacristão na igreja de Nossa Senhora do Rosário, Antônio solicitou ao vigário-geral que aceitasse o breve de dispensa do defeito de nascimento que obtivera em Roma. Em janeiro de 1712, o habilitando argumentava que já estava dispensado na ilegitimidade e no defeito da cor e solicitava que fossem feitas suas inquirições de genere pela parte paterna, de forma a provar sua limpeza de sangue. ${ }^{8}$

Antônio era filho ilegítimo do padre Francisco Cabral de Távora, que, segundo as testemunhas do processo de genere, o tivera ainda no estado secular, e de Teodósia da Fonseca, uma mulher preta do gentio de Angola. Recorde-se que o pai de Antônio depôs como testemunha no processo de genere do primeiro caso aqui narrado. O perfil social deste habilitando era também semelhante ao do anterior, pois seus avós paternos, o capitão Luís Cabral

${ }^{7}$ O porteiro da massa era um dos ofícios da casa real, subordinado ao porteiro-mor, que, nas cerimônias públicas, precedia os cortejos a pé. O ofício de porteiro da massa foi instituído por provisão que juntamente criou as dignidades do cabido e outras funções auxiliares do bispo. Cf Araújo (1822, p. 8).

${ }^{8}$ ACMRJ - HS - Antônio Cabral da Fonseca, 1711-1717. 
de Távora e dona Isabel Tenreira, eram também identificados como "pessoas nobres". Dos avós maternos também não se tinha notícia. ${ }^{9}$ As semelhanças nos caminhos trilhados por Francisco da Costa Maciel e Antônio Cabral da Fonseca rumo ao sacerdócio não parecem ser somente coincidências.

O processo de habilitação de Antônio concluiu-se em 1717. Em 1736, ao redigir seu testamento, o já padre Antônio Cabral da Fonseca apresentou alguns indícios de sua trajetória pós-ordenação. Declarou exercer a função de capelão nas irmandades do Santíssimo Sacramento da Sé, na irmandade de São José e na irmandade de Nossa Senhora do Terço. ${ }^{10}$ As irmandades do Santíssimo, na América portuguesa, eram tradicionalmente redutos das elites locais. Geralmente, eram responsáveis pelo sustento das paróquias, nas quais ocorria a veneração à hóstia consagrada, mediante a manutenção do templo, a realização das despesas com o culto e com a procissão do Corpus Christi (Chahon, 2008, p. 341-344). A irmandade de São José, cuja origem remontava ao século XVII, também apresentava feições elitistas, impondo em seu compromisso o impedimento para a admissão de mouros, judeus e mulatos, regra confirmada em 1730 pela Mesa do Desembargo do Paço (Santos, 2010, p 143). A irmandade de Nossa Senhora do Terço foi instituída no ano de 1722 em um altar da igreja de São José. Entre os seus fundadores e primeiros filiados estavam o capitão Antônio Borges Teixeira, que também era irmão da irmandade do Santíssimo Sacramento da Sé e da Ordem Terceira de São Francisco, ${ }^{11}$ o então governador do Rio de Janeiro que exerceu o cargo de juiz, Aires de Saldanha Albuquerque Coutinho Matos e Noronha, e o mestre de campo $^{12}$ Manoel Gomes da Silva (Salgado et al., 1985, p. 299-300).

Portanto, padre Antônio foi capelão de instituições frequentadas por membros da "boa sociedade", cargo que deve ter alcançado em função das boas relações que manteve. O fato de ter sido sacristão na igreja de Nossa Senhora do Rosário também deve ter lhe aproximado das funções junto às irmandades urbanas. Sob este aspecto, tanto a trajetória de padre Francisco da Costa Maciel quanto a do padre Antônio Cabral da Fonseca confirmam a tendência do clero secular em permanecer de forma mais acentuada nos centros urbanos de

\footnotetext{
9 Idem.

10 ACMRJ - Livro de Óbitos da Freguesia do Santíssimo Sacramento da Sé - LOFSSS - (1746-1758) - Testamento do Padre Antônio Cabral da Fonseca.

"ACMJ - LOFSSS - (1719-1724) - Testamento de Antônio Borges Teixeira.

12 O posto de mestre de campo correspondia a um oficial superior das tropas de fronteiras, cujas atribuições previam fiscalizar as indicações dos capitães de infantaria para provimentos dos postos de alferes e sargentos, aprovando-lhes os regimentos e atestando se prenchiam os requisitos necessários. Cabia-lhe também estar presente quando da apresentação do terço de infantaria, verificando as armas e as montarias. Caso fosse necessário, poderia servir em duas praças, recebendo um soldo de mestre de campo e outro de capitão de infantaria. Nas tropas pagas, por provisão régia de 1747, a patente passou a corresponder à de coronel, tornando-se a mais alta da tropa militar.
} 
maior porte, onde as oportunidades de emprego eram maiores e mais atrativas do ponto de vista dos proventos (Paiva, 2000b, p. 211-212; Faria, 1987, p. 32-33; Salvador, 2012, p. 115).

A oportunidade de amealhar recursos através das funções litúrgicas desempenhadas nas irmandades evidencia-se no caso de padre Antônio quando se compara sua situação no momento em que constituiu seu patrimônio para ordenar-se, em 1717, e aquela que descreveu em seu testamento em 1736. No primeiro momento, Antônio Cabral recebeu em doação de sua mãe e sua irmã uma morada de casas, já entre os bens que listou em seu testamento estavam três moradas de casas, uma sorte de terras e sítio em Pendotiba com forno, roda de fazer farinha e "aferramentos" de trabalho; além de uma chácara em Sacopema com forno, roda e "aferramentos" de trabalho e mais doze escravos. ${ }^{13}$ Ressalte-se que nenhum desses bens foi fruto de herança, pois no mesmo testamento Antônio deixava para a mãe e a irmã a morada de casas que lhe foi doada no momento de constituição de seu patrimônio, enquanto seu pai só lhe legou em testamento a quantia de $30 \$ 000$ (trinta mil réis), que estava muito abaixo dos valores dos bens que declarava. ${ }^{14}$

A carreira sacerdotal parecia afigurar-se de fato como uma estratégia. ${ }^{15} \mathrm{Em} 1713$, o primo do padre Antônio Cabral da Fonseca, o licenciado Vidal Arias Maldonado, solicitou o início de suas inquirições de genere com o objetivo de obter as ordens sacras. Vidal era filho ilegítimo do coronel e cavaleiro professo da Ordem de Cristo Miguel Arias Maldonado e da preta do gentio da Guiné Joana de Jesus. ${ }^{16} \mathrm{O}$ coronel Miguel era irmão do padre Francisco Cabral de Távora e tio do padre Antônio Cabral da Fonseca, e, como já acima assinalado, depôs no processo do padre Francisco da Costa Maciel, sendo seu padrinho de batismo.

Em outubro daquele mesmo ano de 1713, o doutor Gaspar Gonçalves de Araújo, provisor e vigário-geral do bispado do Rio de Janeiro, dispensou Vidal dos defeitos da ilegitimidade e da cor para que pudesse prosseguir em sua habilitação ao sacerdócio. Em 1717 o processo era concluído mediante a finalização das inquirições de patrimônio e vita et moribus, ressalte-se que nesta última inquirição depôs, atestando os bons costumes de Vidal, o padre licenciado Francisco Teles, ${ }^{17}$ a quem me remeterei adiante.

Em 1732, ao redigir seu testamento, o coronel Miguel Arias Maldonado expôs alguns elementos que permitem acompanhar a trajetória pós-ordenação do padre Vidal. O coronel

\footnotetext{
${ }^{13}$ ACMRJ - LOFSSS - (1746-1758) - Testamento do Padre Antônio Cabral da Fonseca.

${ }^{14}$ ACMRJ - LOFSSS - (1719-1724) - Testamento do Padre Francisco Cabral de Távora.

${ }^{15}$ Com base em Giovanni Levi, estou compreendendo estratégia como um conjunto de possibilidades de escolha que visava garantir a segurança do grupo parental em que a preservação do status fundamentava-se na sua transmissão de geração a geração. Assim, os vínculos comportamentais, que demarcavam principalmente a ação social das famílias, atuavam no sentido de melhorar o controle sobre o ambiente social e natural. Cf. Levi (2000, p. 99).

${ }^{16}$ ACMRJ - HS - Vidal Arias Maldonado, 1713-1717.

17 Idem.
} 
nomeou o padre e seu irmão, o capitão João Arias Maldonado, seus testamenteiros e herdeiros. João, assim como Vidal, era fruto da união ilegítima de Miguel Maldonado com a preta Joana de Jesus. Ainda segundo o coronel, seus testamenteiros e herdeiros viviam com ele em seu engenho de fazer açúcar na freguesia de São Gonçalo do Amarante, recôncavo do Rio de Janeiro. Nas terras da propriedade estava localizada uma capela de invocação de Nossa Senhora da Pena, dotada de todos os paramentos necessários para a celebração de missas. ${ }^{18}$ É possível supor que padre Vidal exerceu nessa capela algumas funções litúrgicas.

A posse de oratórios e capelas privadas era um fator de privilégio e distinção social. Os recursos materiais e imateriais necessários para a obtenção dos breves apostólicos e sua validação na respectiva diocese implicavam a reunião de documentos comprobatórios, a constituição de procuradores e a mobilização de influências junto à cúpula da Igreja. Essas capelas, principalmente no interior, como era o caso em questão, eram centros aglutinadores da vida religiosa, funcionando por vezes como alternativas à fundação de paróquias (Chahon, 2008, p. 36-95). Creditavam, portanto, a seus controladores uma posição de influência sobre a vida moral da comunidade (Levi, 2000, p. 192). Tais questões acabavam por reforçar o prestígio local dos seus proprietários, bem como justificavam os investimentos feitos por algumas famílias da elite para que seus filhos fossem colados em paróquias rurais onde aquelas concentravam seus interesses e exerciam mando político (Barral, 2007, p. 29-47).

Entre as funções litúrgicas que padre Vidal desempenharia poderiam estar as obrigações de realizar missas que lhe foram incumbidas por seu pai em testamento. O coronel Miguel deixou ao filho sacerdote metade de umas casas de sobrado que tinha com seu irmão padre Francisco Cabral de Távora, as quais já haviam recebido em herança e que estavam destinadas a produzir rendimentos para que fossem ditas missas anuais pela alma de Estevão de Vasconcelos. O legado era para que padre Vidal, diante da metade que herdava das casas, dissesse meia capela ${ }^{19}$ de missas anualmente. Ainda lhe caberia uma quantia para que dissesse uma capela de missas pelas almas de seus avós paternos. E por fim, o testamento determinava que fosse instituída uma capela anual de missas pela alma do doutor Diogo de Azevedo Coutinho, outro irmão do coronel. O legado indicava que a Santa Casa de Misericórdia ou algum convento ou mosteiro da cidade fossem escolhidos para o seu cumprimento e, caso não aceitassem, que se buscassem as mesmas instituições em Lisboa e, se ainda assim não fosse possível, que padre Vidal se encarregasse de dizer as missas enquanto a quantia não fosse entregue às instituições elencadas. ${ }^{20}$

Desse modo, a construção de capelas e a constituição de capelanias, como em outros

\footnotetext{
${ }^{18}$ ACMRJ - LOFSSS - (1727-1732) - Testamento de Miguel Arias Maldonado.

19 Uma capela corresponde a cinquenta missas.

${ }^{20}$ ACMRJ - LOFSSS - (1727-1732) - Testamento de Miguel Arias Maldonado
} 
lugares da América e Europa, foi um elemento também acionado para dotar os filhos sacerdotes de recursos. No México este expediente foi a base de sustento da maioria dos padres e responsável pelo crescimento do clero secular na primeira metade do século XVIII (Salvador, 2012, p. 122-124). Ao redigir o seu próprio testamento, em 1769, padre Vidal declarou que já não tinha bens com os quais pudesse pagar o que devia e que a fazenda que herdara de seu pai havia sido arrematada em praça pública, estando ele somente na posse das casas encapeladas que lhe foram legadas pelo pai. ${ }^{21}$ Destino bem diferente de seu primo, que aumentara seu patrimônio exercendo a função de capelão em irmandades.

Em 1712, Francisco Teles Barreto, acima mencionado como depoente no vita et moribus de Vidal, foi outro a buscar a vida sacerdotal, partindo de condições semelhantes as já aqui descritas. Disse conhecer Vidal por serem vizinhos e companheiros no curso que haviam concluído. ${ }^{22}$ Talvez fizesse referência a terem estado juntos na universidade, pois Francisco também ostentava o título de licenciado. Era filho ilegítimo do igualmente licenciado Luís Teles de Menezes, que exerceu o cargo de juiz de órfãos e, assim como o pai, também ocupou a provedoria da Santa Casa da Misericórdia, e da parda livre Antônia da Silva. Pelo lado paterno, era neto do capitão Francisco Teles Barreto de Menezes, que também fora juiz de Órfãos e provedor da Santa Casa da Misericórdia do Rio de Janeiro, e de dona Inês de Andrade. Pela via materna, era neto do oficial de tanoeiro João Antônio, nascido no arcebispado de Braga, e de Gracia, do gentio da Guiné. ${ }^{23}$

A família Teles Barreto, entre meados do século XVII e praticamente ao longo de todo o século XVIII, foi senhora de terras e engenhos na freguesia de Jacarepaguá. Os Teles Barreto também ocuparam seguidamente cargos de destaque na República. Além das funções de vereança, o juizado de órfãos tornou-se propriedade da família desde 1658, quando Diogo Lobo Teles o deixou em testamento ao capitão Francisco Teles Barreto de Menezes, que teve a propriedade confirmada por mercê régia em 1661 (Rudge, 1983, p. 87-88). Não é demais lembrar que cabia ao juiz de órfão zelar pela arca dos órfãos, na qual era depositado todo o dinheiro, as dívidas ativas e os rendimentos das fazendas herdados (Fragoso, 2000, p. 61-62). Como administrador deste fundo, o titular do ofício tinha um imenso poder de barganha, já que poderia emprestar os recursos sob sua gestão.

Outro aspecto que distinguiu a família foi a participação de seus membros na administração da Santa Casa da Misericórdia. Instituição fidalga por excelência, na América por-

\footnotetext{
${ }^{21}$ ACMRJ - Livro de Óbitos da Freguesia da Candelária - LOFC - (1764-1778) - Testamento do Padre Vidal Arias Maldonado.

${ }^{22}$ ACMRJ - HS - Vidal Arias Maldonado, 1713-1717.

${ }^{23}$ ACMRJ - HS - Francisco Teles Barreto, 1712-1715; Arquivo Histórico Ultramarino - AHU -"Requerimento do proprietário do juiz de órfãos da cidade do Rio de Janeiro Antônio Teles de Menezes ao Rei D. José I, 1751”, Projeto Resgate, cx. 51, doc. 55; Fazenda (1960, p. 42).
} 
tuguesa procurou reproduzir os padrões exclusivistas previstos no compromisso da Misericórdia lisboeta de 1618. Tanto em Salvador quanto no Rio de Janeiro, os provedores desta irmandade, entre meados do século XVII e do século XVIII, distinguiram-se por sua relação com a grande propriedade fundiária e pela ocupação de cargos governativos, destacando-os como membros de uma nobreza política que tinha na provedoria dessa irmandade um dos elementos que faziam crescer seu prestígio e honra (Russell-Wood, 1981, p. 89-110; Machado, 2015).

Embora o coadjutor da Freguesia da Sé tivesse informado que o habilitando Francisco Teles Barreto andava desencaminhado com uma negra e devendo a várias pessoas, sua ascendência e as boas relações devem ter tido peso para que fosse dispensado dos defeitos da cor e ilegitimidade, além de considerado apto a receber todas as ordens em 1715 . O apoio familiar torna-se mais evidente quando se constata que o doador do patrimônio comprovado por Francisco foi o doutor Antônio Teles Barreto de Menezes, irmão do habilitando e herdeiro do licenciado Luís Teles Barreto. O doutor Antônio herdou não somente as terras, mas também o cargo de juiz de órfãos, perpetuando o controle da família sobre aquele juizado. ${ }^{24}$

É provável que, após ordenar-se, padre Francisco Teles Barreto tenha exercido algumas funções litúrgicas em terras do seu irmão, o doutor Antônio, já que este, em 1722, obteve breve apostólico que o autorizava a manter um oratório privado com direito de celebração de missa diária. Em 1729, um visitador, por ordem do bispo, inspecionou o referido oratório, que estava sob a invocação de Nossa Senhora da Conceição, e constatou estar decentemente ornado com as imagens da santa de invocação com coroa de prata, do Santo Cristo, de São Bento, de Santa Rita, de São José, de São Francisco Xavier, além de cálice de prata, missal, castiçais e pedra de ara. ${ }^{25}$ Em 1730, o sacerdote compareceu como depoente no processo de outro habilitando de cor, Frutuoso Pimenta de Moraes, sendo identificado como escrivão de São Pedro. ${ }^{26}$

A referência dizia respeito a um dos cargos da mesa administrativa da Irmandade de São Pedro dos Clérigos. O compromisso reformado da irmandade, em 1732, determinava que o cargo de escrivão era o segundo em importância na estrutura da organização, tendo a obrigação de substituir o provedor quando necessário. O estatuto ainda determinava que o cargo seria ocupado por um sacerdote de respeito e abonado que pudesse contribuir com

\footnotetext{
${ }^{24}$ ACMRJ - HS - Francisco Teles Barreto, 1712-1715; Rudge (1983, p. 88).

${ }^{25}$ ACMRJ - Breve Apostólico (BA) - Breve de Oratório Privado ao Dr. Antônio Teles de Menezes Juiz de Órfãos filho de Luiz Barreto Teles de Menezes, 1722.

${ }^{26}$ ACMRJ - HS - Frutuoso Pimenta de Moraes, 1709-1730.
} 
uma boa esmola para a irmandade. ${ }^{27}$ Formada majoritariamente por sacerdotes, o sodalício, conforme seu compromisso, admitia seculares "graves e de reconhecida nobreza". ${ }^{28}$ Perfil elitista que se conservou, pelo menos, até fins do século XVIII (Oliveira, 2016). Observa-se, portanto, que padre Francisco Teles Barreto circulou e manteve relações que lhe conferiam algum prestígio em função da distinção que o sacerdócio poderia conferir.

A conclusão desta narrativa traz à cena a história do habilitando Francisco de Sampaio. Seu processo de habilitação, iniciado em 1713, conta que havia sido exposto na porta da casa do capitão Francisco de Sampaio e Almeida quando este servia de juiz ordinário ${ }^{29}$ no Senado da Câmara. Os sete depoentes no processo de genere reiteraram a mesma história, afirmando que nunca se soube quem eram os pais do habilitando e que o capitão Francisco de Sampaio e sua esposa o acolheram e criaram em sua fazenda na freguesia de Irajá, sendo o capitão seu padrinho de batismo. ${ }^{30}$

O capitão Francisco e dona Isabel de Almeida, sua mulher, não tiveram filhos. É possível suspeitar que o habilitando fosse um filho bastardo do capitão, já que a prática da exposição entre as famílias de elite servia como um mecanismo de mascarar atitudes moralmente condenadas e uniões não sancionadas pela Igreja (Brügger, 2007, p. 202-203). Todavia, nenhuma testemunha aventou esta possibilidade, da mesma forma que não se fez nos depoimentos do genere qualquer referência à cor do habilitando. A menção somente apareceu na conclusão do processo de habilitação quando, no vita et moribus, o vigário-geral afirmou que o ordinando estava dispensado na ilegitimidade e na cor e apto a receber todas as ordens sacras. $^{31}$

Assim como os outros habilitandos, Francisco de Sampaio foi devidamente amparado por fortes relações familiares. À época de sua ordenação, o capitão Francisco de Sampaio e Almeida e sua esposa já haviam falecido, no entanto, esta, que morrera depois, deixou em testamento ao ordinando umas casas de sobrado com as quais comprovou seu patrimônio. ${ }^{32}$ Os Sampaio e Almeida constituíram uma família de proprietários fundiários com engenhos nas freguesias de Irajá e Jacarepaguá e com tradição de ocupação de cargos no Senado da

\footnotetext{
${ }^{27}$ AHU - Biblioteca Nacional do Rio de Janeiro, Seção de Manuscritos, códice 1948 - "Compromisso da Irmandade do Pe. São Pedro, Príncipe dos Apóstolos da Cidade de São Sebastião do Rio de Janeiro, 1732", fol. 7-7V.

28 Ibid., fol. 3 .

${ }^{29}$ Cargo eletivo cuja responsabilidade estava em proceder contra aqueles que cometiam crimes no termo do município, exercendo a função de juiz de órfãos quando não houvesse este ofício, passar mandados de prisão e soltura, fiscalizar serviços de estalagens e fixar os seus preços, entre outras funções da municipalidade.

30 ACMRJ - HS - Francisco de Sampaio, 1713-1714.

${ }^{31}$ ACMRJ - HS - Francisco de Sampaio, 1713-1714.

32 Idem.
} 
Câmara. Em seus diversos ramos também originaram uma extensa prole de filhos ilegítimos aos quais procuraram dotar de recursos quando possível (Oliveira, V. L., 2014, p. 117-136).

Francisco de Sampaio foi beneficiário desta rede de proteção, pois em seu processo de vita et moribus constava um termo de obrigação, firmado por Antônio de Sampaio e Almeida, no qual se obrigava a receber o habilitando como capelão em capela sob invocação de São Boaventura que mantinha em sua propriedade no Rio Grande, freguesia de Jacarepaguá. ${ }^{33}$ Antônio era filho legítimo de Manoel de Sampaio e Almeida, irmão do capitão Francisco de Sampaio.

A relação do padre Francisco de Sampaio com a família, ao que tudo indica, intensificou-se, já que, em seu testamento, apresentou elementos que demonstravam que de fato foi residir e exercer suas funções sacerdotais próximo aos Sampaio e Almeida. Declarou o padre que era proprietário de um sítio com casas e benfeitorias, além de quatro escravos, no engenho, em Rio Grande, do capitão Inácio de Sampaio, irmão de Antônio de Sampaio e Almeida. Referiu-se aos irmãos como seus compadres, declarando que tinha conta com eles e com outros moradores do Rio Grande sobre capelas de missas que vinha realizando e que alguns desses moradores ainda o deviam. ${ }^{34}$

As trajetórias dos padres Francisco de Sampaio, Vidal Arias Maldonado e Francisco Teles Barreto aproximam-se sob este aspecto, pois esses sacerdotes acabaram por ir exercer seus múnus em regiões onde suas respectivas famílias tinham propriedades rurais, confirmando o prestígio local delas e atuando de forma a permitir certa interferência na condução moral dos indivíduos que recorriam aos serviços das capelas privadas nas quais atuaram. Conectava-se, portanto, o investimento realizado tanto na ordenação desses sacerdotes quanto na manutenção de lugares de culto que, em função de suas atuações, reforçavam o papel de suas respectivas famílias nas localidades em questão.

Conectam-se também as cinco trajetórias aqui priorizadas em relação às origens étnicas e sociais desses sacerdotes. Todos são frutos de uniões ilegítimas entre pais oriundos de segmentos das elites locais com mães que tinham um passado relacionado à escravidão. Da mesma forma, seus respectivos processos de ordenação denotam estratégias dos grupos nos quais estavam inseridos. Embora não se possa excluir a questão vocacional, que é de difícil percepção e comprovação, mas igualmente importante em uma sociedade católica e profundamente religiosa, não se pode deixar de observar os nexos políticos e sociais que envolvem tais processos. Passo em seguida a tentar perceber essas conexões em um quadro mais amplo.

\footnotetext{
${ }^{33}$ ACMRJ - HS - Francisco de Sampaio, 1713-1714.

34 ACMRJ - LOFSSS - (1737-1740) - Testamento do Padre Francisco de Sampaio.
} 


\section{A ordenação de homens de cor: significados gerais}

De acordo com José Pedro Paiva, uma das maiores dificuldades que se interpõem para a análise do clero secular diz respeito à diversidade da extração social que o compunha, já que era possível encontrar neste segmento tanto filhos segundos ou ilegítimos de famílias fidalgas até setores oriundos do chamado "estado do meio". Nesse sentido, as expectativas desenvolvidas em relação à ordenação eram diversas, passando por estratégias de preservação do patrimônio, afirmação da honra familiar, promoção de ascensão vertical, entre outras. Por outro aspecto, as relações que envolveram a Igreja à época moderna ensejaram conjunturas específicas em relação aos comportamentos dos indivíduos e/ou grupos que desempenharam funções na estrutura eclesiástica. Nesses contextos, ocorreram diversas decisões, negociações e conflitos, sendo ora favorecidos uns e prejudicados outros, mas permitindo, sobretudo, visualizar interesses individuais, familiares, de linhagens e de clientelas que foram construindo estratégias de ação e disputando recursos de poder em conjunturas variadas, para além de uma visão institucional rígida (Paiva, 2012; Paiva, 2000a).

Diante dessas considerações, um primeiro aspecto a ser avaliado diz respeito ao ambiente de recepção das ordenações aqui relatadas. Atentando-se para o conjunto geral das solicitações para ordenação sacerdotal na primeira metade do século XVIII, constatam-se nítidas diferenças no que tange ao registro dos pedidos de acordo com o exercício do múnus episcopal dos três bispos que governaram a diocese do Rio de Janeiro nesse período. ${ }^{35}$

Tabela 1 — Distribuição (\%) das solicitações de habilitações referentes aos "homens de cor" (1702-1745)

\begin{tabular}{|l|c|c|c|}
\hline \multicolumn{1}{|c|}{ BISPOS } & $\begin{array}{c}\text { TOTAL DE } \\
\text { SOLICITAÇÕES } \\
\text { POR PERIODO }\end{array}$ & $\begin{array}{c}\text { NÚMERO DE } \\
\text { SOLICITAÇÕES REFERENTES } \\
\text { AOS “HOMENS DE COR" }\end{array}$ & $\begin{array}{c}\text { PORCENTAGEM DE } \\
\text { SOLICITAÇÕES REFERENTES } \\
\text { DOS “HOMENS DE COR" } \\
\text { EM RELAÇÃO AO TOTAL }\end{array}$ \\
\hline $\begin{array}{l}\text { D. Francisco de São } \\
\text { Jerônimo (1702-1721) }\end{array}$ & 347 & 37 & 10,7 \\
\hline $\begin{array}{l}\text { D. Frei Antônio de } \\
\text { Guadalupe (1725-1740) }\end{array}$ & 83 & 1 & 1,2 \\
\hline $\begin{array}{l}\text { D. Frei João da Cruz } \\
(1741-1745)\end{array}$ & 27 & 1 & 3,7 \\
\hline
\end{tabular}

Fonte: ACMRJ - Habilitações Sacerdotais (1620-1958).

35 O bispado do Rio de Janeiro até 1745 correspondia a uma vasta região que ia da capitania do Espírito Santo ao rio da Prata, possuindo jurisdição eclesiástica sobre o Sul da Bahia, Espírito Santo, Rio de Janeiro, São Paulo, Minas Gerais, Mato Grosso, Goiás, Paraná, Santa Catarina, Rio Grande do Sul e Colônia do Sacramento. 
A série de dados que se inicia no período de D. Francisco de São Jerônimo demarca um significativo aumento no registro dos processos de ordenação, já que, durante o múnus do bispo anterior — D. José de Barros Alarcão (1680-1745) —, contabilizaram-se 147 processos. A ascensão de D. Francisco ao trono episcopal foi demarcada por uma conjuntura de expansão da conquista portuguesa na América assinalada pela descoberta de ouro nas Minas Gerais e pelo crescimento do fluxo migratório, voluntário ou forçado, relacionado à intensificação do tráfico de escravos (Ferreira, 2016, p. 14-15). Esse prelado foi o terceiro bispo do Rio de Janeiro e o primeiro a estabelecer-se de forma mais estável na cadeira episcopal. A história de seus antecessores demonstra grande irregularidade à frente do governo diocesano. O primeiro bispo da diocese - D. Frei Manoel Pereira — foi confirmado em 1676, no entanto, jamais tomou posse do bispado, renunciando ao cargo em 1680. O segundo bispo, D. José de Barros Alarcão, indicado em 1680, tomou posse da diocese através de seu procurador, chegando ao Rio de Janeiro somente em 1682. Em 1689 já estava de volta à Lisboa para prestar esclarecimentos à Coroa, retornando ao Rio somente em 1700, ano de sua morte (Oliveira, 2015). Tais fatores combinados podem explicar o aumento dos pedidos de ordenação e o empenho de D. Francisco em dotar o bispado de sacerdotes que pudessem dar conta da população crescente de fiéis.

Todavia, a diminuição das solicitações de ordenações que marca os governos episcopais seguintes é inversamente proporcional ao crescimento populacional, que teve continuidade. Desse modo, outros fatores devem ser considerados, mesmo levando em consideração que o período do bispo D. Frei João da Cruz foi bem menor quando comparado com seus antecessores.

Defendo que esta significativa diferença guarda relação com a espiritualidade a qual estavam ligados D. Frei Antônio de Guadalupe e D. Frei João da Cruz. Ambos eram adeptos do movimento de reforma religiosa que ficou conhecido como jacobeia. A jacobeia foi um movimento de renovação religiosa nascido no início do século XVIII entre os Eremitas de Santo Agostinho, no Colégio da Graça de Coimbra, e que, posteriormente, propagou-se para outros claustros portugueses. De tendência apegada à ortodoxia e defensora de uma profunda austeridade, fazia uma crítica à relaxação dos costumes nos claustros e na sociedade de uma forma geral. A consecução desse projeto e sua expansão dependeriam em especial de um clero, tanto regular quanto secular, bem formado e de conduta exemplar, de modo que este estilo de vida pudesse transformar-se na orientação moral no reino e em suas conquistas. O rigorismo que assinalou a postura assumida por esses dois bispos na condução da diocese do Rio de Janeiro pode ser explicado por esse comprometimento, refletindo-se em uma maior exigência nos processos de ordenação sacerdotal de uma forma geral e dos descendentes de africanos e escravos em particular (Oliveira, 2015).

Diante dessas questões e a partir dos dados da Tabela l parece-me possível tentar compreender alguns sentidos que foram dados às ordenações dos chamados homens de cor, situando em um quadro mais amplo as narrativas que abriram este texto. 
De forma a dimensionar as expectativas desses ordinandos em relação ao sacerdócio, parece-me correto iniciar pela tentativa de melhor precisar suas origens sociais. Em termos de filiação, dos 39 casos identificados, 26 eram filhos naturais ou ilegítimos, e 13, filhos legítimos. No que tange à condição jurídica dos pais, l era forro e 38 não tiveram sua condição identificada, presumindo-se, portanto, que se tratavam de homens livres. Entre as mães, 18 eram forras, 3 eram escravas, 1 era livre e 17 não tiveram condição mencionada, presumindo-se da mesma forma que eram livres. Em relação à cor, 7 pais a tiveram identificada, sendo 2 mulatos e 5 pardos. Entre as mães, 25 tiveram menção de cor, sendo 4 mulatas, 10 pardas e 11 pretas.

A maior proporção de mulheres forras e escravas identificadas entre as mães pode explicar, em parte, o maior índice de filhos ilegítimos, já que o percentual de filhos naturais entre as forras foi bastante alto na América portuguesa (Brügger, 2007, p. 54). Dois outros dados importantes dizem respeito à desproporção entre a menção à condição e à cor das mães e dos pais. Há uma proporção maior de pais livres e sem cor, o que pode apontar para uma profunda assimetria entre as uniões que deram origem aos habilitandos. Outro índice que julgo importante diz respeito à titulação ou ocupação dos pais. Entre os 39 casos, conseguiu-se identificar essa referência em relação a 25 pais, de acordo com apresentado no Quadro l:

Quadro 1 - Título/Ocupação dos pais dos habilitandos

\begin{tabular}{|l|c|}
\hline \multicolumn{1}{|c|}{ TítULO/OCUPAÇÃO } & $\mathbf{N}^{\circ}$ \\
\hline Religiosos & 2 \\
\hline Padre secular & 1 \\
\hline Padre secular licenciado e vigário & 1 \\
\hline Padre secular capelão & 1 \\
\hline Alferes & 1 \\
\hline Capitão e juiz de órfãos & 1 \\
\hline Capitão e vereador & 1 \\
\hline Coronel e cavaleiro da Ordem de Cristo & 1 \\
\hline Licenciado e juiz de órfãos & 1 \\
\hline Licenciado & 2 \\
\hline Lavrador & 2 \\
\hline Terceiro de São Francisco* & 1 \\
\hline $\begin{array}{l}\text { Vivia de sua roça e de mineirar (Itatiaia nas Minas) } \\
\text { e hoje também do seu negócio (no Rio de Janeiro) }\end{array}$ & 1 \\
\hline Soldado & 8 \\
\hline Oficiais mecânicos & 1 \\
\hline
\end{tabular}

Fonte: ACMRJ - Habilitações Sacerdotais (1620-1958)

*Considerado como um título, pois foi acionado pelo próprio declarante pelo fato do pertencimento às Ordens Terceiras distinguirem elementos de uma elite, geralmente branca, na América portuguesa. 
O que é dado à observação permite constatar que parte significativa dos pais ostentava títulos ou ocupações que denotavam a pertença a segmentos de uma elite política e econômica, notadamente os eclesiásticos, os que ostentavam títulos de alta patente militar combinados, por vezes, com cargos de governança — vereador e juiz de órfãos — além da comenda da Ordem de Cristo. Os dois religiosos que ocupam o topo da tabela e pertenciam à Ordem de São Francisco eram filhos da chamada nobreza da terra, respectivamente Alberto Gago da Câmara e Domingos de Castro, o primeiro, filho do capitão Lopo Gago da Câmara e dona Úrsula da Silveira, ${ }^{36}$ e o segundo, filho do capitão Alexandre de Castro e de dona Felipa de Castro, esta da família do governador Salvador Correia de Sá. Dois dos padres que também estão na tabela tinham perfil semelhante, eram os já referidos Antônio Cabral da Fonseca e Francisco da Costa Maciel. Ressalte-se também aqueles pais que tinham grau universitário, o que, a partir do século XVII, em Portugal, passou a denotar grau de nobilitação (Hespanha, 1994, p. 310)

Os demais pais, seguindo uma tendência constatada entre o clero português moderno, vinham do chamado estado do meio (Paiva, 2012) e foram identificados como oficiais mecânicos, lavradores e soldados. Embora, na América portuguesa e mesmo na Europa, o termo lavrador pudesse designar setores enriquecidos de proprietários rurais que possuíam um maior status (Schwartz, 1988, p. 247-248; Tackett, 1979, p. 215).

Quanto aos que se designaram como Terceiros de São Francisco, em relação a um deles não há como precisar melhor sua posição, embora ao longo do Setecentos tenha predominado, entre os membros desta Ordem Terceira, os setores oriundos das atividades mercantis, destacando-se o papel dos "negociantes de grosso trato" na ocupação dos cargos de direção da ordem (Martins, 2009, p. 349-352).

O outro terceiro franciscano trata-se de Gaspar Galhete de Andrade, pai de Manoel Francisco Pereira, que se ordenou em 1712. Gaspar, em 1691, foi provido na serventia do ofício de provedor das Minas de Paranaguá pelo governador-geral do Brasil, Antônio Luís Gonçalves da Câmara Coutinho. Acredito que o mesmo não chegou a tomar posse, pois, em 1692, há uma alegação de motivos ao Conselho Ultramarino, feita pelo provedor da fazenda do Rio de Janeiro, justificando não dar posse a Gaspar Galhete. Na alegação, o provedor da fazenda argumentava que aquela nomeação não competia ao governador-geral e sim a ele, provedor, como administrador das minas. ${ }^{37}$ De qualquer forma, a indicação pelo governa-

\footnotetext{
${ }^{36}$ Ele, camarista por duas vezes (filho do capitão de fortaleza Pedro Gago da Câmara), e ela, cunhada de Diogo Lobo Teles, que fora capitão de infantaria e juiz de órfãos, e de Francisco Teles Barreto, acima mencionado, além de ter como irmãos Francisco da Silva Vilasboas, que fora vigário geral do bispado, e Antônio da Silveira Vilasboas, vereador uma vez, e pai de Inácio da Silveira Vilasboas, vereador por duas vezes, e Francisco da Silveira Soutomaior, que fora desembargador do Tribunal da Relação na Bahia.

${ }^{37}$ Anais da Biblioteca Nacional do Rio de Janeiro, v. XXXIX, 1917, p. 190; AHU - Rio de Janeiro, cx. 5, doc. 548.
} 
dor-geral atestava o cabedal e as boas relações mantidas com o topo da hierarquia social pelo pai do padre Manoel Francisco.

Mesmo entre aqueles em que os pais foram identificados como oficiais mecânicos havia um grau de relação parental estabelecida com setores da nobreza da terra e mesmo da nobreza reinol. Eram os casos dos habilitandos Francisco Martins da Silva - filho do oficial de barbeiro Francisco Martins e afilhado de batismo do capitão Alexandre de Castro acima referido - e de Francisco Caeiro Teles, também filho de um oficial de barbeiro, Paulo Caeiro, e também afilhado de batismo de Dom Cristóvão, conde em Portugal de uma vila cujo nome não se pode identificar em decorrência do estado da documentação. A mãe de Francisco Caeiro Teles, Luiza Teles, tivera como tutor o antigo governador de Mazagão, Dom Cristóvão de Melo, que não tenho certeza tratar-se do mesmo padrinho de batismo de seu filho, mas é uma possibilidade. ${ }^{38}$

Outro índice que talvez ajude a esclarecer as origens e relações dos habilitandos pode ser reforçado pela titulação ou ocupação dos avós paternos. Entre esses foram identificadas 16 menções que se distribuíam da seguinte maneira:

Quadro 2 - Título/Ocupação dos avós paternos

\begin{tabular}{|l|c|}
\hline \multicolumn{1}{|c|}{ TítULO/OCUPAÇÃO } & N $^{\circ}$ \\
\hline Capitão & 7 \\
\hline Alferes & 1 \\
\hline Doutor & 2 \\
\hline Escrivão de capela & 1 \\
\hline Lavrador & 2 \\
\hline Homens do mar & 2 \\
\hline Ofício mecânico & 1 \\
\hline \multicolumn{2}{|c|}{ Fonte: ACMRJ - Habilitações Sacerdotais (1620-1958) }
\end{tabular}

Assim como os pais, os avós paternos, na sua maioria, ostentavam títulos militares destacados, graus universitários e um cargo burocrático outorgado por mercê régia e bastante rentável, que era o caso do escrivão de capelas. ${ }^{39}$ Essa conjunção pode indicar, guardando as devidas proporções, uma apropriação de parte de uma mentalidade característica das nobre-

\footnotetext{
${ }^{38}$ ACMRJ - HS - Francisco Martins da Silva (1711-1718); Francisco Caeiro Teles (1709-1713).

39 Ofício de provisão régia que, entre outras atribuições, deveria promover, juntamente com o provedor e o tesoureiro de defuntos e ausentes, a execução dos testamentos, fazer inventários, escrituras e papéis de pessoas falecidas sem deixar herdeiros. Cabia-lhe ainda fazer o leilão público de todo bem móvel lançado em inventário e dos bens de raiz com o conhecimento dos herdeiros. Tinha também sob sua guarda uma das chaves do cofre em que se guardavam os valores dos bens arrecadados. Cf. Salgado et al. (1985, p. 200-201).
} 
zas europeias. Ou seja, a tendência de encaminhar as proles bastardas para as carreiras militar e eclesiástica, procurando garantir-lhes o futuro, livrando-as de condições mais subalternas, e salvaguardando a honra e o prestígio das famílias (Bols, 1966, p. 21-22). A identificação também de um percurso relacional no qual os habilitandos estavam envolvidos, a exemplo dos filhos dos oficiais mecânicos apadrinhados por setores da nobreza da terra e reinol, pode igualmente reforçar o papel de reprodução social no qual a mobilidade desempenhava um papel de manter inalterada a classificação social (Olival, Monteiro, 2003; Monteiro, 2012, p. $50,75)$. A carreira sacerdotal, portanto, era aventada como uma possibilidade de garantir a ascensão das proles ilegítimas e marcadas pelo estigma da escravidão. Neste sentido, a própria dispensa do defeito da cor já indicava um grau de mudança de estado na medida em que suspendia uma das principais máculas de origem em uma sociedade escravista.

Do ponto de vista da conjuntura social, o acesso dos descendentes de africanos ao sacerdócio parecia expressar, entre fins do século XVII e primeira metade do século XVIII, certa seletividade, pois, de alguma forma, a condição social dos pais e avós paternos acabava sendo um fator destacado. ${ }^{40} \mathrm{O}$ que parece não ter sido uma particularidade deste segmento, já que, entre 1702 e 1721, durante o episcopado de D. Francisco de São Jerônimo, os habilitandos de uma forma geral advinham de setores sociais semelhantes (Ferreira, 2016, p. 61).

Sob este aspecto, reforçou-se o empenho dessas famílias em dotar seus filhos de condições para a ordenação. Um fator a ser considerado nesse conjunto de esforços diz respeito à constituição do patrimônio. Cabe ressaltar que, dos 39 habilitandos, 29 apresentaram seu processo de patrimônio, sendo possível identificar claramente o conteúdo de 27 processos, em 2, o estado da documentação impossibilitou a identificação.

As Constituições sinodais de Lisboa, que vigoraram na América portuguesa até a promulgação das Constituições primeiras do arcebispado da Bahia, em 1707, estabeleciam que o patrimônio a ser comprovado deveria ter valor mínimo de $150 \$ 000$ (cento e cinquenta mil réis), produzindo um rendimento anual de $12 \$ 000$ (doze mil réis) [Cunha, 1656, p. 101]. As constituições baianas, que foram seguidas pelos bispados do Brasil e de Angola, foram mais exigentes ao estabelecerem $400 \$ 000$ (quatrocentos mil réis) como valor mínimo para o patrimônio com rendimento anual de $25 \$ 000$ (vinte e cinco mil réis). A título de comparação, um escravo adulto, no Rio de Janeiro entre 1671 e 1720, atingiu valores entre $84 \$ 000$ (oitenta e quatro mil réis) e $198 \$ 000$ (cento e noventa e oito mil réis). Já na Bahia, por volta de 1705, esse valor chegava aos $200 \$ 000$ (duzentos mil réis) [Sampaio, 2003, p. 121; Mattoso, 1988, p. 92]. Tais valores demonstram que o acesso à ordenação não era algo que estava franqueado a

40 Os processos relativos à segunda metade do século XVIII demarcam uma mudança na condição social dos progenitores dos habilitandos, indicando uma mobilidade um pouco maior dos grupos subalternos e médios que conseguiram que seus filhos ascendessem em maior número ao sacerdócio. Cf. Oliveira (2014, p. 350-353). 
todos que desejassem. Contudo, como o patrimônio na maioria das vezes era constituído por meio de doações de parentes dos ordinandos, o papel das famílias e suas estratégias para ordenar seus filhos parecem ser evidentes (Ferreira, 2016, p. 51-52).

Entre os 27 processos de patrimônio legíveis, 12 tiveram os pais como doadores, 9 foram adquiridos pelo próprio ordinando, sendo que, entre estes, um adquiriu uma casa com recursos que recebeu do testamento de sua benfeitora, outro declarou que comprovou o patrimônio com herança que lhe foi deixada pelo antigo senhor. Seis indivíduos tiveram outras pessoas doando o patrimônio, entre estes, um recebeu doação do cunhado e da irmã, outro recebeu doação do irmão, enquanto um terceiro recebeu doação da madrinha e do tio materno. Os três restantes receberam doações de pessoas cujo vínculo com o ordinando não foi possível estabelecer. De qualquer forma, o peso da parentela na constituição do patrimônio é destacado, o que não era uma particularidade somente dos ordinandos de cor.

Outro dado que também pode reforçar o papel da família diz respeito à formação intelectual dos ordinandos. No conjunto dos habilitandos, pode-se identificar que dez deles já tinham grau universitário completo quando deram início a seus pedidos de ordenação, enquanto dois tinham graus universitários incompletos. ${ }^{41}$ Nesse sentido, 1/3 praticamente dos ordinandos havia tido contato com estudos universitários, embora isso não fosse uma exigência para a ordenação. O investimento na formação intelectual, que no caso da América portuguesa era mais complexo em função da inexistência de universidades instaladas na colônia, ao contrário da América espanhola, poderia potencializar a obtenção de posições mais privilegiadas na carreira eclesiástica, como se constata para outras áreas na Europa e na Nova Espanha (Faria, 1987, p. 33; Salvador, 2012, p. 119-121). A trajetória do padre Francisco da Costa Maciel parece confirmar esta tendência, já que sua chegada ao notariado apostólico, além das suas relações pessoais, só foi possível graças a sua formação.

O que se pode perceber no contraste das análises individuais, colocadas em perspectiva aos dados gerais, é a semelhança das estratégias adotadas pelas famílias de modo a promover os seus filhos. Algumas dessas famílias, como é possível ver nos casos dos padres Francisco da Costa Maciel, Antônio Cabral da Fonseca e Vidal Arias Maldonado, tinham laços bastante próximos, o que implicava que o sucesso alcançado por um pudesse estimular a repetição das estratégias para o outro. Os pais de Vidal e Antônio Cabral, os irmãos coronel Miguel Arias Maldonado e padre Francisco Cabral de Távora, que foram testemunhas no processo de Francisco da Costa Maciel, adotaram a mesma estratégia com suas proles ilegítimas, escolhendo a carreira sacerdotal como forma de encaminhar seus rebentos. O padre

\footnotetext{
${ }^{41}$ Para um estudo sobre a presença dos homens de cor na Universidade de Coimbra, no século XVIII, analisando esse acesso enquanto fator de mobilidade e os percalços daqueles que, mesmo obtendo títulos universitários, tiveram sua ascensão impedida em função da cor, cf. Reginaldo (2018).
} 
Francisco Teles Barreto afirmou ter tido convivência estudantil com Vidal Arias Maldonado, um parente de Francisco Teles por parte de sua avó paterna, o habilitando Francisco Gago Pereira, filho ilegítimo do já mencionado Alberto Gago e Antônia Ribeira do gentio da Guiné, que também possuía o título de licenciado, ${ }^{42}$ o que pode demonstrar que estas famílias viram na formação intelectual um caminho propício para melhor posicioná-los socialmente e, talvez, garantir um melhor trajeto na carreira sacerdotal.

O sacerdócio, portanto, mantinha-se como uma função socialmente atrativa que poderia gerar ganhos materiais e simbólicos para o indivíduo e para o grupo familiar. Em relação às proles mestiças, que traziam a marca da ascendência escrava e africana, a mobilidade social conseguida através da ordenação não só abria novas possibilidades para aqueles indivíduos como funcionava para distanciá-los da desonra, que deixava de pesar tanto sobre eles quanto sobre os ramos fidalgos da família, notadamente a paterna, como foi possível visualizar nos casos aqui analisados. Com efeito, o investimento neste tipo de ordenação promovia uma mobilidade que reiterava os padrões hierárquicos já existentes e criava outros ao estabelecer novas desigualdades entre os segmentos de cor. Desse modo, como afirma Evaldo Cabral de Mello, tais práticas que demarcaram a América portuguesa associaram ao pecado original da escravidão os valores do Antigo Regime, "contribuindo assim para a reprodução dos sistemas de dominação" (Mello, 2000, p. 13).

\section{Referências}

ARAÚJO, José de Azevedo Pizarro e. Memórias históricas do Rio de Janeiro. Rio de Janeiro: Tipografia de Silva Porto, 1822, tomo VI.

BARRAL, María Elena. De sotanas por la Pampa: religión y sociedade en el Buenos Aires rural tardocolonial. Buenos Aires: Prometeo Libros, 2007.

BOLS, Karl. Castas, ordens e classes na Alemanha. In: MOUSNIER, Roland (Org.). Problemas de estratificação social. Lisboa: Livraria Martins Fontes, 1966.

BRÜGGER, Silvia Maria Jardim. Minas patriarcal: família e sociedade (São João del-Rei - séculos XVIII e XIX). São Paulo: Annablume, 2007.

CHAHON, Sergio. Os convidados para a ceia do senhor: as missas e a vivência leiga do catolicismo na cidade do Rio de Janeiro e arredores (1750-1820). São Paulo: Edusp, 2008.

CUNHA, Dom Rodrigo da. Constituições sinodais do arcebispado de Lisboa. Lisboa: Oficina de Paulo Craesbeek, 1656.

FARIA, Ana Mouta. Função da carreira eclesiástica na organização do tecido social do Antigo Regime. Ler História (Lisboa). n. 11, p. 29-46, 1987.

FAZENDA, José Vieira. Os provedores da Santa Casa da Misericórdia do Rio de Janeiro. Rio de Janeiro: Fundação Romão de Mattos Duarte, 1960.

FERREIRA, Fernanda Vinagre. O clero secular no bispado do Rio de Janeiro e o múnus episcopal de D. Francisco de São Jerônimo (1702-1721). Dissertação (Mestrado), Universidade Federal do Estado do Rio de Janeiro. Rio de Janeiro, 2016.

${ }^{42}$ ACMRJ - HS - Francisco Gago Pereira (1704-1711). 
FRAGOSO, João. A nobreza da República: notas sobre a formação da primeira elite senhorial do Rio de Janeiro (séculos XVI e XVII). Topoi: Revista de História (Rio de Janeiro). n. 1, p. 45-122, 2000.

HESPANHA, António Manuel. Às vésperas do Liviathan: instituições e poder político. Portugal, século XVII. Coimbra: Almedina, 1994.

LEMAITRE, Nicole. Des cures tridentins militants? In: LEMAITRE, Nicole (dir.). Histoire des cures. Paris: Fayard, 2002, p. 181-202.

LEVI, Giovanni. A herança imaterial. Trajetória de um exorcista no Piemonte do século XVII. Rio de Janeiro: Civilização Brasileira, 2000.

MACHADO, Karoline Marques. A caridade nos territórios ultramarinos. Notas sobre a trajetória dos provedores da Misericórdia do Rio de Janeiro, IV EJIHM, Porto, 2015. Disponível em: http:// ejihm2015.weebly.com/uploads/3/8/9/1/38911797/ ejihm_2015_kmarques.pdf. Acesso em: 22 jun. 62016.

MARTINS, William de Souza. Membros do corpo místico: ordens terceiras no Rio de Janeiro (c. 1700- c. 1822). São Paulo: Edusp, 2009.

MATTOSO, Kátia de Queirós. Ser escravo no Brasil. 2. ed. São Paulo: Brasiliense, 1988.

MELLO, Evaldo Cabral. O nome e o sangue: uma parábola familiar no Pernambuco colonial. 2. ed. Rio de Janeiro: Topbooks, 2000.

MONTEIRO, Nuno Gonçalo. Elites e poder: entre o Antigo Regime e o Liberalismo. 3. ed. Lisboa: ICS, 2012.

OLIVAL, Fernanda; GARCIA, Leonor Dias; LOPES, Bruno; SEQUEIRA, Ofélia. Testemunhar e ser testemunha em processos de habilitação (Portugal, século XVIII). In: LÓPEZ-SALAZAR, Ana Isabel; OLIVAL, Fernanda; FIGUEIRÔA-RÊGO, João (Coord.). Honra e sociedade no mundo ibérico e ultramarino. Inquisição e ordens militares, séculos XVI-XIX. Lisboa: Edições Caleidoscópio, 2013, p. 315-349.

OLIVAL, Fernanda; MONTEIRO, Nuno Gonçalo. Mobilidade social nas carreiras eclesiásticas em Portugal (1500-1820). Análise Social, v. XXXVII, n. 165, p. 1213-1239, 2003.

OLIVEIRA, Anderson José Machado de. Os proces- sos de habilitação sacerdotal dos homens de cor: perspectivas metodológicas para uma história social do catolicismo na América portuguesa. In: FRAGOSO, João; GUEDES, Roberto; SAMPAIO, Antônio Carlos Jucá de (orgs.). Arquivos paroquiais e história social na América portuguesa. Rio de Janeiro: Mauad X, 2014, p. 329-362.

OLIVEIRA, Anderson José Machado de. A administração do sacramento da ordem aos negros na América portuguesa: entre práticas, normas e políticas episcopais (1702-1745). Revista Locus (Juiz de Fora). v. 41, p. 415-442, 2015.

OLIVEIRA, Anderson José Machado de. A Irmandade de São Pedro dos Clérigos do Rio de Janeiro (c. 1790-c. 1820): reforma do clero, distinções e hierarquias sociais. In: AYROLO, Valentina; OLIVEIRA, Anderson José Machado de (Coord.). Historia de clérigos y religiosas en las Américas: conexiones entre Argentina y Brasil (siglos XVIII y XIX). Buenos Aires: Teseo, 2016, p. 151-190.

OLIVEIRA, Anderson José Machado de. "Dispensamos o suplicante in defectu coloris": em torno da cor nos processos de habilitação sacerdotal no bispado do Rio de Janeiro (1702-1745). Topoi: Revista de História (Rio de Janeiro). v. 21, n. 45, 2020.

OLIVEIRA, Victor Luiz Alvares de. Retratos de família: sucessão, terras e ilegitimidade entre a nobreza da terra de Jacarepaguá, séculos XVI-XVIII. Dissertação (Mestrado), Universidade Federal do Rio de Janeiro, Rio de Janeiro, 2014.

PAIVA, José Pedro. A Igreja e o poder. In: AZEVEDO, Carlos Moreira (Dir.). História religiosa de Portugal. Lisboa: Círculo de Leitores, v. 2, 2000a, p. 135 186.

PAIVA, José Pedro. Os mentores. In: AZEVEDO, Carlos Moreira (Dir.). História religiosa de Portugal. Lisboa: Círculo de Leitores, v. 2, 2000b, p. 209-225.

PAIVA, José Pedro. As comunicações no âmbito da Igreja e da Inquisição. In: NETO, Margarida Sobral (Coord.). As comunicações na Idade Moderna. Lisboa: Fundação Portuguesa das Comunicações, 2005, p. $147-176$

PAIVA, José Pedro. Os bispos de Portugal e do império 
1495-1777. Coimbra: Imprensa da Universidade de Coimbra, 2006.

PAIVA, José Pedro. Um corpo entre outros corpos sociais: o clero. Revista de História das Ideias (Coimbra). n. 33, p. 165-182, 2012.

REGINALDO, Lucilene. "Não tem informação": mulatos, pardos e pretos na Universidade de Coimbra (1700-1771). Estudos Ibero-Americanos (Porto Alegre). v. 44, n. 3, p. 421-434, 2018.

RUDGE, Raul Telles. As sesmarias de Jacarepaguá. São Paulo: Livraria Kosmos, 1983.

RUSSELL-WOOD, A. J. R. Fidalgos e filantropos. A Santa Casa da Misericórdia da Bahia, 1550-1755. Brasília: Editora da UnB, 1981.

SALGADO, Graça et al. Fiscais e meirinhos: a administração no Brasil Colonial. 2. ed. Rio de Janeiro: Nova Fronteira, 1985.

SALVADOR, Rodolfo Aguirre. Un clero en transición. Población clerical, cambio parroquial y política eclesiástica en el arzobispado de México, 1700-1749. México: Unam, 2012.
SAMPAIO, Antônio Carlos Jucá de. Na encruzilhada do Império: hierarquias sociais e conjunturas econômicas no Rio de Janeiro (c. 1650-c. 1750). Rio de Janeiro: Arquivo Nacional, 2003.

SANTOS, Beatriz Catão Cruz. Irmandades, oficiais mecânicos e cidadania no Rio de Janeiro do século XVIII. Varia Historia (Belo Horizonte). v. 43, n. 26, p. 131-153, 2010

SCHWARTZ, Stuart B. Segredos internos: engenhos e escravos na sociedade colonial. São Paulo: Companhia das Letras, 1988.

TACKETT, Thimothy. L'histoire sociale du clergé diocésain dans la France du XVIII ' siècle. Revue d'histoire Moderne et Contemporaine (Paris). v. 26, n. 2, p. 198-234, abril-juin, 1979.

VALVERDE, María Luisa Garcia. Los notarios apostólicos de Granada a través de las legislaciones civil y eclesial. Historia. Instituciones. Documentos (Sevilla).

v. 37, p. 87-108, 2010.

VIDE, Sebastião Monteiro da. Constituições primeiras do arcebispado da Bahia (introdução e edição de Bruno Feitler e Evergton Sales Souza). São Paulo: Edusp, 2010. 